\title{
Depósitos litorâneos neoproterozóicos do Grupo Alto Paraguai no sudoeste do Cráton Amazônico, região de Mirassol d'Oeste, Mato Grosso
}

\author{
José Bandeira Cavalcante da Silva Júnior', Afonso César Rodrigues Nogueira ${ }^{2}$, Setembrino \\ Petri $^{3}$, Claudio Riccomini ${ }^{4}$, Ricardo Ivan Ferreira Trindade ${ }^{5}$, Alcides Nóbrega Sial ${ }^{6}$ \& \\ Renata Lourenço Hidalgo ${ }^{7}$
}

Resumo Eventos anômalos do final do Neoproterozóico têm sido documentados principalmente nas seqüências de capas carbonáticas de diversas regiões do planeta. Condições climáticas extremas envolveram glaciações globais que foram associadas com significativas mudanças oceanográficas e variações do nível do mar. As sucessões carbonáticas neoproterozóicas geralmente são sucedidas por depósitos siliciclásticos que em diversas regiões, como na América do Sul, são pobremente descritas e com história sedimentar ainda pouco entendida. No sul do Cráton Amazônico, região central do Brasil, o Grupo Alto Paraguai é um excelente exemplo de depósitos siliciclásticos que sobrepõem a seqüência de capa carbonática do Grupo Araras depositadas após a glaciação do final do Criogeniano. Esta unidade foi investigada com base na análise de fácies e estratigráfica na região de Mirassol d'Oeste, Estado do Mato Grosso e consiste, da base para o topo, de duas sucessões: 1) camadas amalgamadas e cimentadas por dolomita espática de arenito fino a médio, com estratificações cruzadas hummocky e swaley, laminações plano-paralela e truncada por ondas, estratificação cruzada acanalada, marcas onduladas, gretas de dissecação e moldes de evaporitos, interpretados como depósitos litorâneos influenciados por maré e tempestades (Formação Raizama, Base do Grupo Alto Paraguai); e 2) pelito, folhelho e arenito fino a médio com marcas onduladas, laminação plano-paralela e estratificação cruzada swaley, interpretados como depósitos de plataforma marinha e face litorânea inferior (Formação Sepotuba). O cimento de dolomita espática ferrosa exibe cristais com faces e clivagens curvadas típicos de saddle dolomite. Valores isotópicos negativos de carbono $(-1,70 \%$ a $-3,56 \%)$ e oxigênio $(-3,78 \%$ a $-5,17 \%$ o) confirmam a cimentação tardia com influência de fluídos meteóricos e hidrotermais durante o soterramento profundo. O limite entre essas sucessões é uma discordância superimposta por uma superfície transgressiva ou de inundação marinha que representa o onlap sobre uma zona litorânea instalada na borda sul do Cráton Amazônico durante o Neoproterozóico.

Palavras-chave: Cráton Amazônico, Grupo Alto Paraguai, Análise de fácies, Dolomita espática, isótopos de C e O.

Abstract Neoproterozoic littoral deposits of Alto Paraguai Group in the southeastern Amazon Craton, Mirassol D'oeste region, Mato Grosso. Anomalous events of terminal Neoproterozoic have been mostly reported in the cap carbonate sequences exposed in many regions worldwide. Extreme climatic conditions involving global glaciations were associated with significant oceanographic and sea-level changes. Neoproterozoic carbonate successions commonly are succeeded by siliciclastics deposits that in many regions, like in South America, are poorly described and have their sedimentary history still poorly understood. In the southwestern Amazon craton, central region of Brazil, the Alto Paraguai Group is an excellent example of silicilastic deposits that overlie the post-Marinoan cap carbonate sequence of the Araras Group. The Alto Paraguai Group was investigated using facies and stratigraphic analysis in the Mirassol d'Oeste region, State of Mato Grosso, and consists of two successions: 1) amalgamated fine to medium-grained sandstone, cemented by sparry dolomite, with swaley and hummocky cross-stratifications, wave truncated and even-parallel laminations, trough cross stratification, ripple mark, dessication cracks and evaporite molds, interpreted as storm and tidal influenced littoral deposits; and 2) pelite, shale and fine to medium-grained sandstone with ripple marks, even parallel lamination and swaley cross stratification, interpreted as offshore to lower shoreface deposits. Sparry ferrous dolomite cement in sandstone exhibits crystals with frequent curved faces and cleavages, typical of saddle dolomite. Isotopic negative values of carbon $(-1,70 \%$ to $-3,5 \%$ ) and oxygen $(-3,78 \%$ o to $-5,17 \%$ ) confirm late cementation with influence of meteoric and hydrothermal waters during deep burial diagenesis. The limit between these successions is an unconformity superimposed by marine flooding or transgressive surface, that records an onlap over a littoral zone installed in the southern border of the Amazon craton during the Neoproterozoic.

Keywords: Amazon craton, Alto Paraguai Group, facies analysis, sparry dolomite, $\mathrm{C}$ and $\mathrm{O}$ isotopes.

1 - Programa de Pós-Graduação em Geologia Regional e Ambiental, Depart. de Geociências, Universidade Federal do Amazonas, Manaus, AM, Brasil. E-mail: jotabandeira@gmail.com

2 - Programa de Pós-Graduação em Geologia Regional e Ambiental, Universidade Federal do Amazonas, Manaus, AM, Brasil; Faculdade de Geologia, Instituto de Geociências, Universidade Federal do Pará, Belém, PA, Brasil e Pesquisador CNPq, E-mail: anogueira@ufpa.br

3 - Depart. de Geologia Sedimentar e Ambiental, Instituto de Geociências, USP, São Paulo, SP, Brasil, E-mail: petri@usp.br

4 - Depart. de Geologia Sedimentar e Ambiental, Instituto de Geociências, USP. São Paulo, SP, Brazil e pesquisador CNPq, riccomin@usp.br.

5 - Depart. de Geofísica, Inst. de Astronomia, Geofísica e Ciências Atmosféricas, USP, São Paulo, SP, Brasil, pesquisador CNPq. E-mail: rtrindad@ iag.usp.br

6 - NEG-LABISE, Depart. de Geologia, Univ. Federal de Pernambuco, Recife, PE, Brasil e pesquisador CNPq. E-mai: sial@ufpe.br

7 - Programa de Pós-Grad. em Geologia Sedimentar e Ambiental, IGc, USP, São Paulo, SP, Brasil, E-mail: renatabiol1@hotmail.com 
INTRODUÇÃO A história evolutiva da Terra no final do Pré-Cambriano é atualmente alvo de intensos debates sobre as condições paleoambientais extremas relacionadas às glaciações globais, mudanças oceanográficas e variações do nível do mar, concomitantes com o aparecimento das primeiras formas complexas de vida (Kaufman \& Knoll 1995, Jacobsen \& Kaufman 1999, Knoll 2000, Nogueira et al. 2007). Estes eventos anômalos têm sido documentados principalmente nas seqüências de capas carbonáticas neoproterozóicas ocorrentes em diversas regiões cratônicas do planeta (Hoffman \& Schrag 2002, Halverson et al. 2004, Allen \& Hoffman 2005, Nogueira et al. 2007). Estas seqüências ou megaciclos são geralmente recobertas por depósitos siliciclásticos que são elementos importantes na composição do "quebra-cabeças" evolutivo de muitas bacias neoproterozóicas. Estes megaciclos formados pela alternância de carbonatos e rochas siliciclásticas sugerem um controle global ou interregional no estilo sedimentar, e representam a evolução de plataformas marinhas carbonáticas e siliciclásticas (Narbonne et al. 1994, Walter et al. 2000, Jiang et al. 2003, Halverson et al. 2005, Condon et al. 2005, Allen \& Leather 2006). No Brasil, vários estudos vêm sendo realizados sobre os depósitos carbonáticos pós-glaciais da Faixa Paraguai e do Cráton Amazônico considerados de idade Ediacarana (630-542 Ma), que inclui a primeira capa carbonática descrita na América do Sul, inserida na hipótese de Snowball Earth (Nogueira et al. 2003, Allen \& Hoffman 2005, Halverson et al. 2006). Estes depósitos carbonáticos são sucedidos por rochas siliciclásticas do Grupo Alto Paraguai, ainda pouco entendidas do ponto de vista faciológico e estratigráfico. As sucessões sedimentares estudadas à sul do Cráton Amazônico, região de Mirassol d'Oeste, correspondem ao topo da Formação Raizama, constituída por arenitos carbonáticos, e à base da Formação Sepotuba, composta por pelitos e arenitos (Fig. 1). Além da interpretação de depósitos litorâneos e marinhos, este estudo permitiu situar estratigraficamente no Grupo Alto Paraguai os arenitos cimentados por carbonato da região de Mirassol d'Oeste, anteriormente posicionados na sucessão carbonática do Grupo Araras (Barros et al. 1982).

O SUL DO CRÁTON AMAZÔNICO A borda sul do Cráton Amazônico encontra-se limitada pela Faixa Paraguai (Almeida 1964a, 1965) e recoberta por depósitos sedimentares que datam do Neoproterozóico, Paleozóico e Cenozóico (Barros et al. 1982, Almeida 1984, Alvarenga \& Saes 1992, Nogueira 2003, Nogueira et al. 2003, Nogueira \& Riccomini 2006). As rochas sedimentares apresentam-se distribuídas descontinuamente, margeando as partes sul (Mirassol d'Oeste) e sudeste (região de Tangará da Serra) do Cráton Amazônico, com mergulhos sub-horizontais sobre rochas cristalinas, principalmente granitos, gnaisses e rochas metassedimentares do Grupo Aguapeí (Almeida 1984, Alvarenga \& Saes 1992, Nogueira et al. 2003, 2007). A unidade que recobre as rochas do embasamento é constituída por diamictitos glaciogênicos da Formação
Puga, correlatos à glaciação global do final do Criogeniano, de $635 \mathrm{Ma}$ (Nogueira et al. 2003, Alvarenga et al. 2004). Os carbonatos do Grupo Araras recobrem bruscamente os diamictitos, guardando o registro de mudanças das condições climáticas glaciais para as de efeito estufa, no contexto da hipótese de Snowball Earth (Hoffman \& Schrag 2002, Nogueira et al. 2003). Somente as unidades mais basais do Grupo Araras, as formações Mirassol d'Oeste e Guia, estão representadas na região de Mirassol d'Oeste, sendo que unidades mais superiores, as formações Serra do Quilombo e Nobres (dolomitos e arenitos dolomíticos), comumente encontradas na Faixa Paraguai (Nogueira \& Riccomini 2006), ainda não foram observadas. A sucessão estudada recobre o Grupo Araras e inclui a base do Grupo Alto Paraguai formada por arenitos e pelitos da Formação Raizama, além de folhelhos e arenitos da Formação Sepotuba (Fig. 1). O grupo ainda apresenta mais uma unidade, a Formação Diamantino (ritmitos vermelhos, arenitos finos e conglomerados) que não aflora na região de Mirassol d'Oeste, sendo restrita à porção oriental da Faixa Paraguai (Almeida 1964a, Barros et al. 1982). Estas unidades são interpretadas como depósitos glácio-marinhos, de plataforma carbonática, litorâneos, lacustre e deltaico (Fig. 1).

Os depósitos siliciclásticos do Grupo Alto Paraguai sucederam a deposição carbonática do Grupo Araras e se relacionam diretamente com áreas-fonte associadas aos blocos soerguidos a sul do cráton, que produziram abundante influxo de terrígenos (Nogueira 2003, Nogueira \& Riccomini 2006). Estas áreas soerguidas foram articuladas à colisão de blocos continentais relacionada aos eventos finais do Brasiliano/ Pan-Africano (Almeida 1984) de idade eocambriana a ordoviciana (540-490 Ma) e teria ocorrido durante a Orogênese Paraguai (Basei \& Brito Neves 1992) ou Pampeana-Araguaia (Tohver et al. 2006). Eventos distensivos posteriores resultaram na intrusão local de corpos graníticos com idade de cerca de $500 \mathrm{Ma}$, fornecida pela datação radiométrica do Granito São Vicente (Almeida \& Mantovani 1975).

\section{A SUCESSÃO SEDIMENTAR DO GRUPO ALTO}

PARAGUAI Os depósitos sedimentares estudados têm sua melhor exposição nas pedreiras da região de Mirassol d'Oeste, em especial na Pedreira Império, onde alcançam cerca de $70 \mathrm{~m}$ de espessura (Figs. $1 \mathrm{e}$ 2). As rochas do Grupo Alto Paraguai são predominantemente siliciclásticas, sendo constituídas por diferentes fácies sedimentares distribuídas em duas sucessões (Tab. 1). Os afloramentos da região são descontínuos lateralmente e grande parte das melhores exposições está relacionada aos arenitos com cimento carbonático, que são explorados na região para a pavimentação de pisos e estradas. Apenas as fácies da Sucessão 1 possuem cimentação carbonática (Fig. 2). A sucessão de fácies apresenta-se localmente modificada por falhas, que por vezes verticalizam o acamamento original. Fraturas, estilólitos e cavidades (vugs) preenchidas por calcita e dolomita espática ocorrem próximo a cavernas 


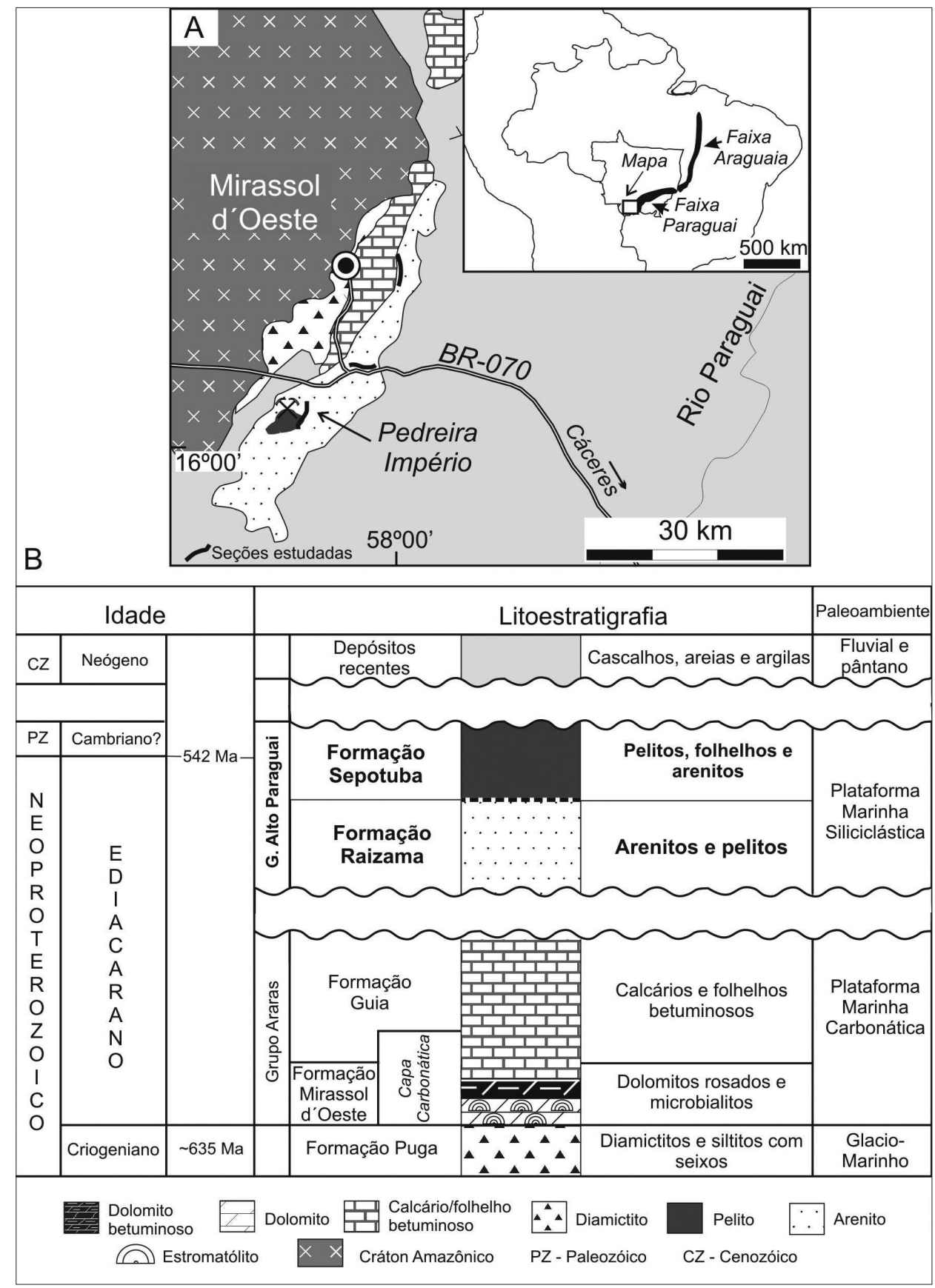

Figura 1 - Localização da área e posicionamento estratigráfico das unidades estudadas. A) Região de Mirassol d'Oeste, com destaque para a Pedreira Império e seções estudadas. B) O Grupo Alto Paraguai está representado pelas formações Raizama e Sepotuba.

e podem alcançar desde 2 metros de altura até uma dezena de metros.

Sucessão 1 A Sucessão 1 compreende arenito fino a médio, bem selecionado, com grãos subarredondados a arredondados, cimentado por carbonato, formando camadas de até $90 \mathrm{~cm}$ de espessura, às vezes amalgamadas. Predomina a estratificação cruzada tipo swaley e secundariamente hummocky (respectivamente, fácies As e Ah), com comprimento de onda de até $7 \mathrm{~m}$ e 1,3 $\mathrm{m}$ de amplitude (Fig. 3B). A fácies As é lateralmente contínua por dezenas de metros, passando para estratifi- cação e/ou laminação plano-paralela (fácies Ap) e laminação cruzada de baixo-ângulo (fácies Apb), geralmente associadas com marcas onduladas assimétricas e, subordinadamente, simétricas, recobertas por mud drapes (Fig. 3C). A laminação ondulada exibe lateralmente espessamento e adelgaçamento sistemático formando um padrão tipo pinch-and-swell (Fig. 3A). Arenito médio a grosso, com grânulos e grãos subangulosos a arredondados, mal selecionados, exibem estratificação cruzada acanalada de médio porte (fácies Aa), com sets de até $50 \mathrm{~cm}$ de espessura, e camadas lateralmente contínuas por dezenas de metros (Fig. 2). 


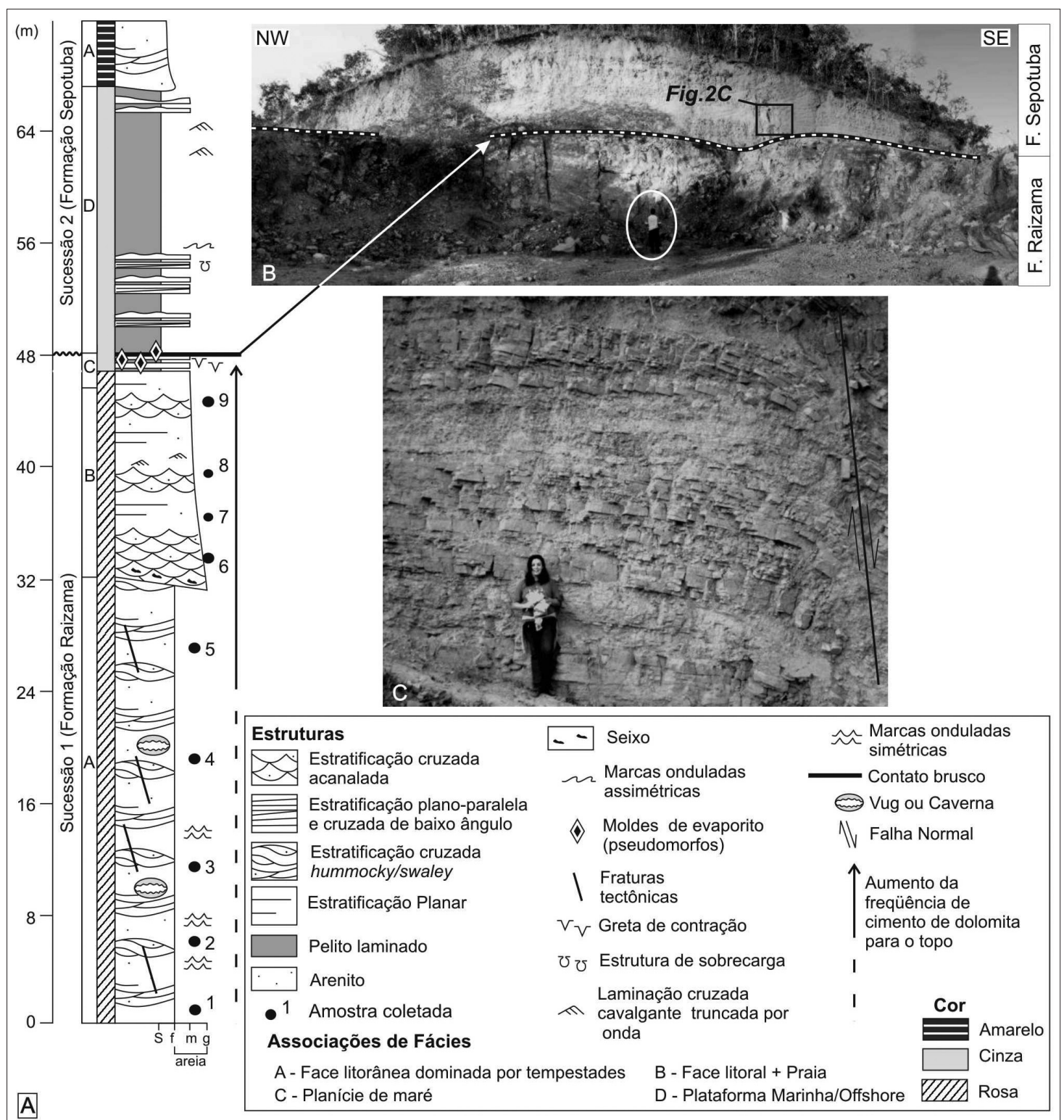

Figura 2 - O Grupo Alto Paraguai na região de Mirassol d'Oeste. Perfil estratigráfico (A) e seção panorâmica da Pedreira Império (B). O contato brusco entre as duas sucessões estudadas (1 e 2) é marcado pela ocorrência de gretas de contração (vide perfil). A Sucessão 2 é caracterizada pela alternância de pelitos/folhelhos e arenitos, muitas vezes rotacionados por falhas $(C)$.

No topo da sucessão ocorrem camadas centimétricas de arenito muito fino com marcas onduladas simétricas e assimétricas, às vezes com padrão de interferência e recobertas por mud drapes. Associados às marcas onduladas ocorrem pseudomorfos de cristais de evaporitos (Fig. 4B) e principalmente gretas de contração (fácies Ag), classificadas em dois grupos: 1) gretas ortogonais, completas, dispostas aleatoriamente e orientadas (Figs. 4A e B); e 2) gretas incompletas, sinuosas e fusiformes (Figs. $4 \mathrm{~B}$ e C). Internamente, as camadas da fácies Ag exibem acamamento maciço e, subordinadamente laminação cruzada.

A Sucessão 1 é caracterizada pela quase ausência de pelitos e principalmente por camadas de arenitos com estratificações cruzadas swaley e hummocky que indicam a atuação de ondas de tempestades (Duke \& Prave 1992, Cheel \& Leckie 1993). A predominância de camadas de arenito amalgamadas sugere tempestitos proximais depositados na face litorânea intermediária a superior. Esta zona é caracterizada pelo retrabalhamento dos sedimentos por forte fluxo oscilatório, combinado com componentes unidirecionais (Walker \& Plint 1992). Períodos mais energéticos foram responsáveis pelo desenvolvimento da laminação plana. Durante o declínio das tempestades, os eventos erosivos induzidos pela componente oscilatória teriam gerado as camadas com estratificações cruzadas tipo swaley e hummocky, posteriormente retrabalhadas por marcas onduladas. Os depósitos de face litorânea com tempestitos, passam verticalmente para fácies depositadas em águas mais rasas, sugerindo a diminuição da lâmina d'água para o 
Tabela 1 - Fácies e processos sedimentares do Grupo Alto Paraguai na região de Mirassol d'Oeste.

\begin{tabular}{|c|c|c|}
\hline Litotipos & Estruturas & Processos \\
\hline Folhelho/Pelito laminado (Pl). & Laminação plano-paralela. & Deposição a partir de suspensão. \\
\hline $\begin{array}{l}\text { Arenito muito fino a fino, com grãos } \\
\text { arredondados, e siltitos subordinados } \\
\text { (ASc). }\end{array}$ & $\begin{array}{l}\text { Laminação cruzada cavalgante super- } \\
\text { crítica. Marcas onduladas recobertas } \\
\text { por mud drapes. }\end{array}$ & $\begin{array}{l}\text { Migração de marca ondulada e deposi- } \\
\text { ção a partir de suspensão. }\end{array}$ \\
\hline $\begin{array}{l}\text { Arenito fino com grãos bem seleciona- } \\
\text { dos e arredondados (Ap). }\end{array}$ & $\begin{array}{l}\text { Laminação plano-paralela e lineação de } \\
\text { partição. }\end{array}$ & $\begin{array}{l}\text { Deposição por suspensão e correntes } \\
\text { trativas em lençol, em regime de fluxo } \\
\text { superior. }\end{array}$ \\
\hline $\begin{array}{l}\text { Arenito muito fino a fino, com grãos } \\
\text { bem arredondado }(\mathrm{Ag}) \text {. }\end{array}$ & $\begin{array}{l}\text { Gretas de contração ortogonais e in- } \\
\text { completas. }\end{array}$ & $\begin{array}{l}\text { Exposição subaérea e desidratação su- } \\
\text { baquosa de material fino a coloidal (si- } \\
\text { nerése). }\end{array}$ \\
\hline $\begin{array}{l}\text { Arenito fino a médio, bem selecionado, } \\
\text { com grãos arredondados (Ah). }\end{array}$ & $\begin{array}{l}\text { Estratificação cruzada hummocky. La- } \\
\text { minação plano-paralela e laminação } \\
\text { cruzada de baixo-ângulo. }\end{array}$ & $\begin{array}{l}\text { Deposição por fluxo combinado domi- } \\
\text { nantemente oscilatório resultante do } \\
\text { declínio de tempestade. Deposição por } \\
\text { fluxo em lençol (flat bed). }\end{array}$ \\
\hline $\begin{array}{l}\text { Arenito fino a médio, bem selecionado } \\
\text { e com grãos arredondados (As). }\end{array}$ & $\begin{array}{l}\text { Estratificação cruzada swaley de médio } \\
\text { porte, estratificações plano-paralela e } \\
\text { cruzada de baixo ângulo a ondulante. }\end{array}$ & $\begin{array}{l}\text { Fluxo combinado com predominância } \\
\text { da componente unidirecional, relacio- } \\
\text { nado ao declínio de tempestade. Depo- } \\
\text { sição por fluxo em lençol. }\end{array}$ \\
\hline $\begin{array}{l}\text { Arenito fino a médio, moderadamente } \\
\text { selecionado com grãos subarredonda- } \\
\text { dos a arredondados (Apb). }\end{array}$ & $\begin{array}{l}\text { Marcas onduladas simétricas e assi- } \\
\text { métricas recobertas por mud drape. } \\
\text { Laminação plano-paralela e laminação } \\
\text { cruzada de baixo ângulo a lateralmente } \\
\text { ondulada com padrão pinch-and-swell. }\end{array}$ & $\begin{array}{l}\text { Alternância de deposição a partir de } \\
\text { corrente e fluxo oscilatório. Deposi- } \\
\text { ção por suspensão durante períodos de } \\
\text { águas paradas. }\end{array}$ \\
\hline $\begin{array}{l}\text { Arenito médio a grosso com grânulos, } \\
\text { mal selecionado, com grãos subangulo- } \\
\text { sos a arredondados (Aa). }\end{array}$ & $\begin{array}{l}\text { Estratificação cruzada acanalada de } \\
\text { médio porte. Segregação de grãos gros- } \\
\text { sos nos foresets. }\end{array}$ & $\begin{array}{l}\text { Migração de barras do tipo } 3 \mathrm{D} \text {, em } \\
\text { regime de fluxo inferior, induzida por } \\
\text { correntes. }\end{array}$ \\
\hline
\end{tabular}

topo da sucessão (shallowing upward).

Os arenitos médios a grossos com estratificação plano-paralela e truncamento de baixo ângulo foram gerados em nível de energia mais alto, relacionado aos processos de fluxo e refluxo em ambiente de praia. Os arenitos com estratificação cruzada acanalada refletem a migração de dunas subaquosas, induzida pela corrente litorânea na porção superior da face litorânea (Walker \& Plint 1992). As camadas centimétricas capeadas por gretas de contração, marcas onduladas e, eventualmente, moldes de cristais de evaporitos, indicam alternância de processos trativos em lâmina d'água muito rasa e exposição subaérea recorrente, que são característicos de zona de intermaré (Dalrymple 1992). A morfologia cúbica dos pseudomorfos é indicativa de halita e caracteriza paleoambiente hipersalino e árido sob condições de temperatura acima de $35^{\circ} \mathrm{C}$ (Goodall et al. 2000).

Sucessão 2 A Sucessão 2 corresponde a intercalações de folhelhos, pelitos e arenitos finos subordinados.
É muito mal exposta na região estudada. Sua melhor ocorrência é na Pedreira Império e adjacências, onde alcança até $20 \mathrm{~m}$ espessura (Figs. 1 e 2). Arenitos finos com laminação plana (fácies Ap), marcas onduladas e laminação cruzada de baixo ângulo (fácies $\mathrm{Apb}$ ) formam camadas de espessura centimétrica, lateralmente contínuas, que se intercalam com a fácies $\mathrm{Pl}$, preferencialmente próximo ao contato com a Sucessão 1. Arenitos finos com estratificação cruzada swaley (fácies As) formam camadas de até $5 \mathrm{~m}$ de espessura e encontramse no topo da sucessão aflorante.

Os folhelhos e pelitos laminados representam os litotipos de mais baixa energia da Sucessão 2 e indicam deposição a partir de suspensão durante condições normais de sedimentação na zona de costa afora (offshore) ou na transição para a face litorânea inferior (cf. Walker \& Plint 1992). Esta deposição tranqüila era interrompida eventualmente por influxos de areia induzidos por fluxos oscilatórios gerados por eventos de tempestades como indicado pelas fácies Ap, Apb e As. 

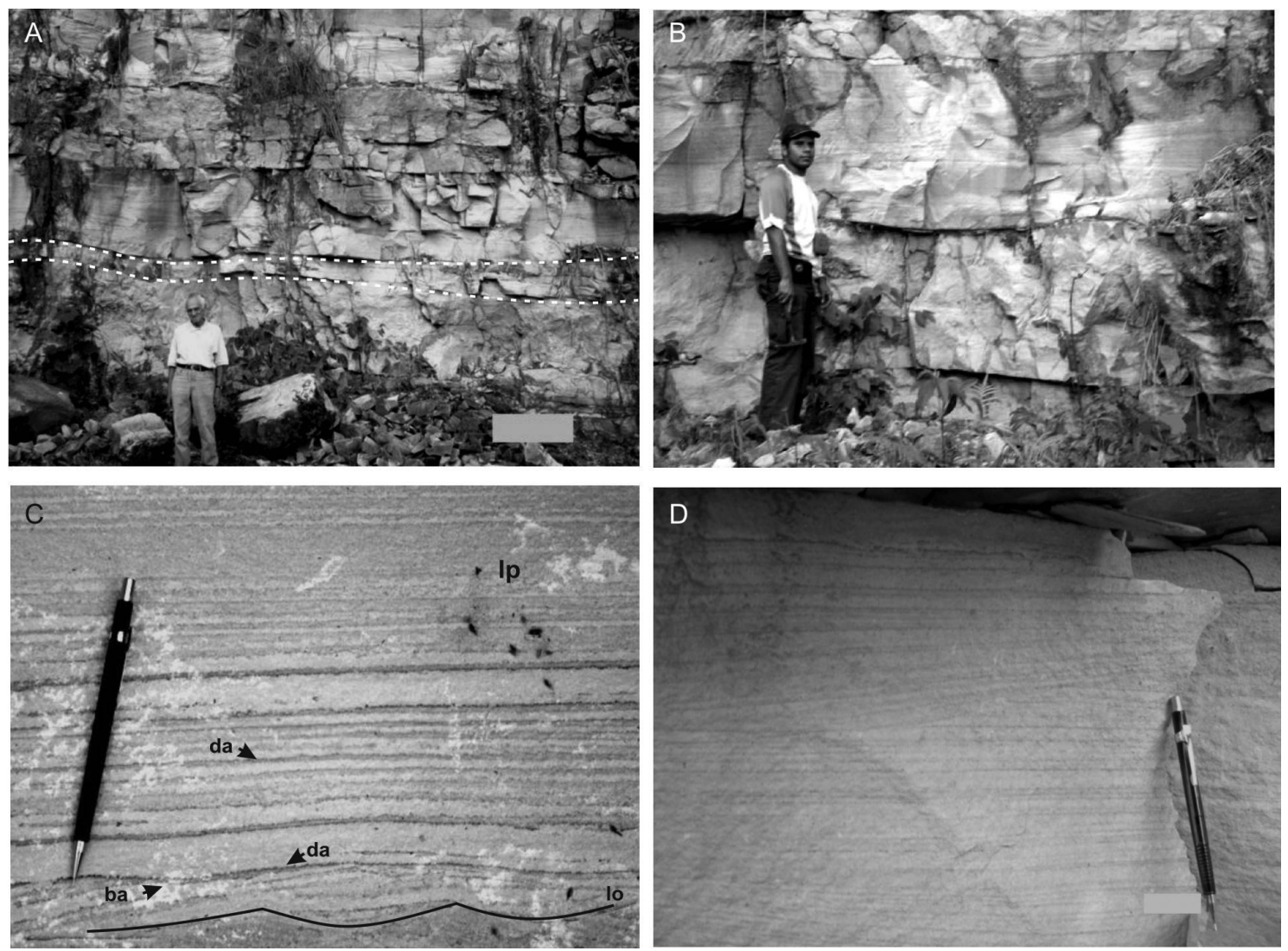

Figura 3 - Fácies sedimentares dos depósitos litorâneos. A) Geometria deposicional da fácies As, composta por acamamentos de megamarcas onduladas, com adelgaçamento e espessamento sistemático das camadas. B) Camadas separadas por superficies erosivas onduladas, internamente exibindo estratificação cruzada swaley (fácies As). C) Estruturas produzidas por ondas representadas por laminação plana a ondulante (lp, lo), laminação cruzada de baixo ângulo (ba), às vezes com mud drapes (da) (fácies Ap e Apb). D) Laminação plana com truncamento de baixo ângulo (fácies As).

Fluxos oscilatórios gerados por tempestitos são desacelerados em águas profundas, resultando na deposição de camadas arenosas mais contínuas (Myrow 1992). O declínio deste fluxo de onda causaria o retrabalhamento das camadas, gerando laminação plana e marcas onduladas (De Raaf et al. 1977).

O limite entre as sucessões 1 e 2 O limite entre as sucessões 1 e 2 do Grupo Alto Paraguai na região de Mirassold'Oeste, é planar e brusco (Figs. 1 e 2). Embora a continuidade desta superfície não tenha sido mapeada na região estudada, a nítida distinção dos paleoambientes das sucessões 1 e 2 sugere quebra importante na história deposicional. A Sucessão 1 é um registro de trato de sistema de mar alto representado por depósitos de plataforma rasa (Formação Raizama) organizados em ciclos de raseamento ascendente de face litorânea. Os ciclos próximos à superfície de contato exibem sucessivos estratos com gretas de contração e moldes de evaporitos, indicativos de proeminente rebaixamento do nível de base deposicional e, conseqüentemente, exposição subaérea ou bypassing (cf. Van Wagooner et al. 1988). A ocorrência de folhelhos de plataforma de costa afora da Sucessão 2 (Formação Sepotuba) ime- diatamente sobre este limite, indica aumento abrupto da lâmina d'água que caracteriza também uma superfície transgressiva. Assim, o contato entre as sucessões 1 e 2 que representam respectivamente tratos de sistemas de mar alto e transgressivo, é interpretado como um limite de seqüência amalgamado com uma superfície transgressiva.

\section{OS ARENITOS CARBONÁTICOS DO GRUPO}

ALTO PARAGUAI Arenitos com cimento carbonático, aflorantes na região de Mirassol d'Oeste, têm sido considerados como pertencentes às rochas carbonáticas do Grupo Araras (Almeida 1964b, Barros et al. 1982, Alvarenga \& Trompette 1992). A falta de estudos sedimentológicos e estratigráficos de detalhe nestas rochas sem uma investigação petrográfica do carbonato têm favorecido esta interpretação estratigráfica até o momento. Para definir melhor as características petrográficas destes arenitos, e principalmente do cimento, foram descritas 9 seções delgadas distribuídas ao longo da Sucessão 1 (Fig. 2). Valores de isótopos de carbono e oxigênio do cimento foram obtidos no Laboratório de Isótopos Estáveis da Universidade Federal de Pernambuco (NEG-LABISE), no intuito de determinar a 

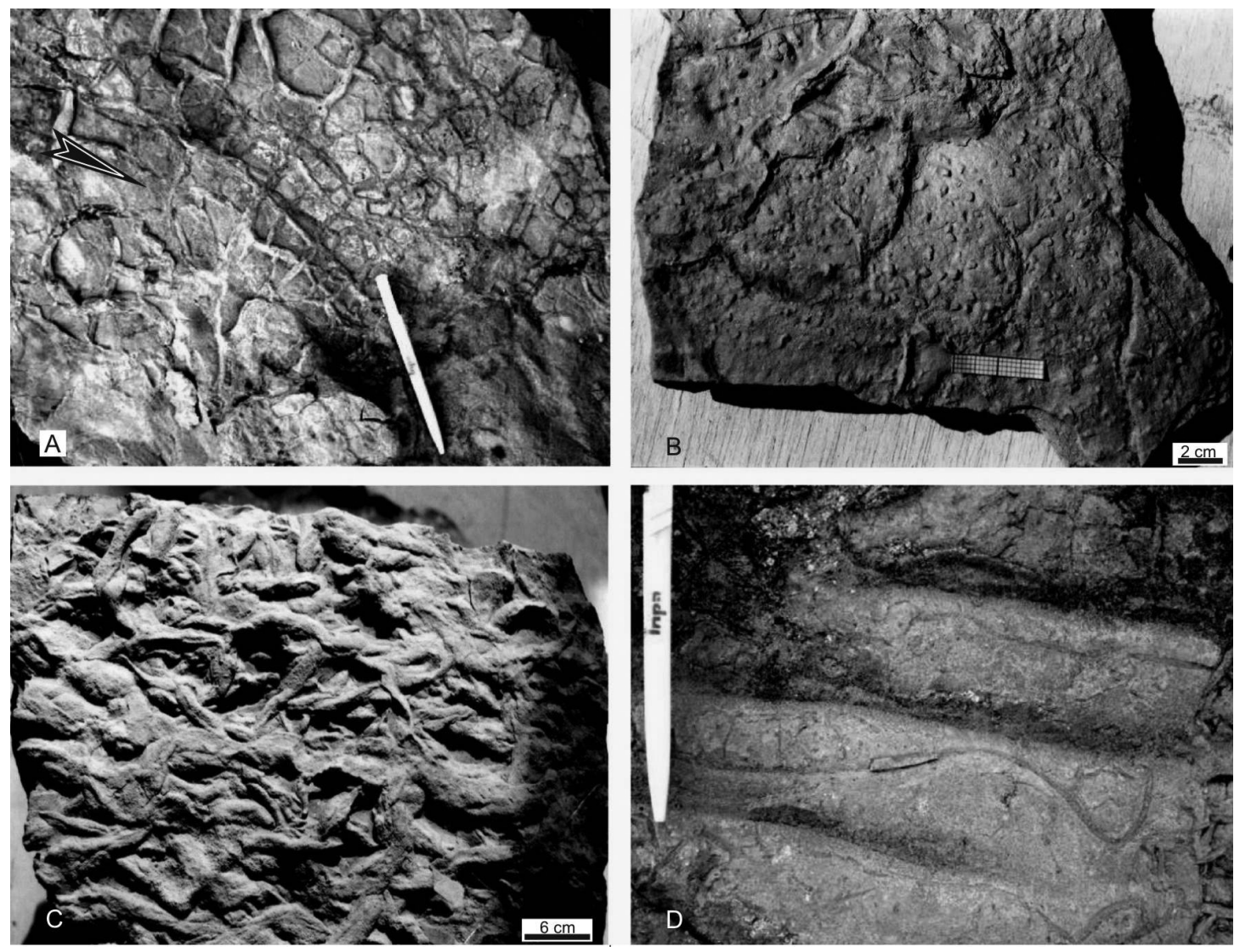

Figura 4 - Padrões de gretas de contração da fácies Ag. A) Gretas de contração ortogonais, passando lateralmente (seta) de padrão aleatório para padrão ordenado. B) Pseudomorfos de cristais cúbicos, provavelmente de halita (contra molde), em horizonte gretado. C) Gretas ortogonais do tipo fusiforme em vários níveis sobrepostos. D) Greta de contração sinuosa semicircular preservada em calhas de marcas onduladas (contra molde).

composição isotópica de carbono e oxigênio, e complementar as interpretações diagenéticas. Os resultados foram registrados por notações convencionais em por mil (\%) relativo ao padrão Pee Dee Belemnite (VPDB). As incertezas das medidas de isótopos foram $0,1 \%$ para carbono e $0,2 \%$ para oxigênio, baseado em múltiplas análises de um padrão interno do laboratório (BSC; Borborema Skarn Calcite). Além disso, os carbonatos e pelitos foram melhor caracterizados por difração de raios-X no laboratório da Universidade Federal do Amazonas, e por meio de imagens de microscopia eletrônica de varredura (MEV) obtidas no laboratório da Universidade Federal do Pará.

Petrografia Os arenitos carbonáticos do Grupo Alto Paraguai foram classificados, segundo Folk (1974), como quartzo-arenitos de granulometria fina a média, com quartzo variando de $95 \%$ a $96 \%$. Os grãos de quartzo são predominantemente monocristalinos e apresentam sobrecrescimento sintaxial. Ocorrem ainda grãos de plagioclásio e microclínio ( $3 \%$ a $2 \%$ ), sílex e siltito ( $2 \%$ a $1 \%$ ), bem como argilominerais autigênicos (illita e caulinita). A calcita é outro tipo de cimento carbonático encontrados na sucessão 1 e ocorrem exclusivamente preenchendo fraturas e cavidades de dissolução.

A cimentação dos arenitos é dolomítica e varia da base da sucessão aflorante com uma proporção de $10 \%$, ultrapassando a porcentagem de grãos detríticos de quartzo no topo e alcança até $90 \%$ de dolomita espática, concentrando-se no limite com a Sucessão 2 (Fig. 2). A reação do cimento com solução de ferricianeto de potássio revelou tom de azul claro, indicando composição ferrosa para dolomita. A textura deste carbonato é idiotópica a hipidiotópica, com cristais que variam de 10 a $70 \mu \mathrm{m}$, com tamanho médio de aproximadamente $40 \mu \mathrm{m}$. Ocorrem também textura poiquilotópica, confirmada nas imagens de microscopia eletrônica de varredura (MEV) (Fig. 5A e B). Muitos cristais rômbicos apresentam núcleo com aspecto nublado e bordas levemente mais claras. A coloração da dolomita varia desde o tom mais comum, o branco, até as cores marrom e rosa resultantes de inclusões de óxido de ferro. A presença de óxido de ferro é também indicada pela coloração castanha clara que confere discreta zonação aos cristais. O contato entre alguns cristais de dolomita apresenta limite de compromisso na forma de zig-zag e suturado, representando a competição dos cristais durante a cimentação. As faces e clivagem curvadas, extinção ondulante e diâmetro superior a $30 \mu \mathrm{m}$ caracterizam o tipo saddle dolomite (Choquette 1971, Folk \& Assereto 1974, Radke \& Marthis 1980) (Fig. 5C).

$\mathrm{O}$ cimento precipitou-se em poros e fraturas da 

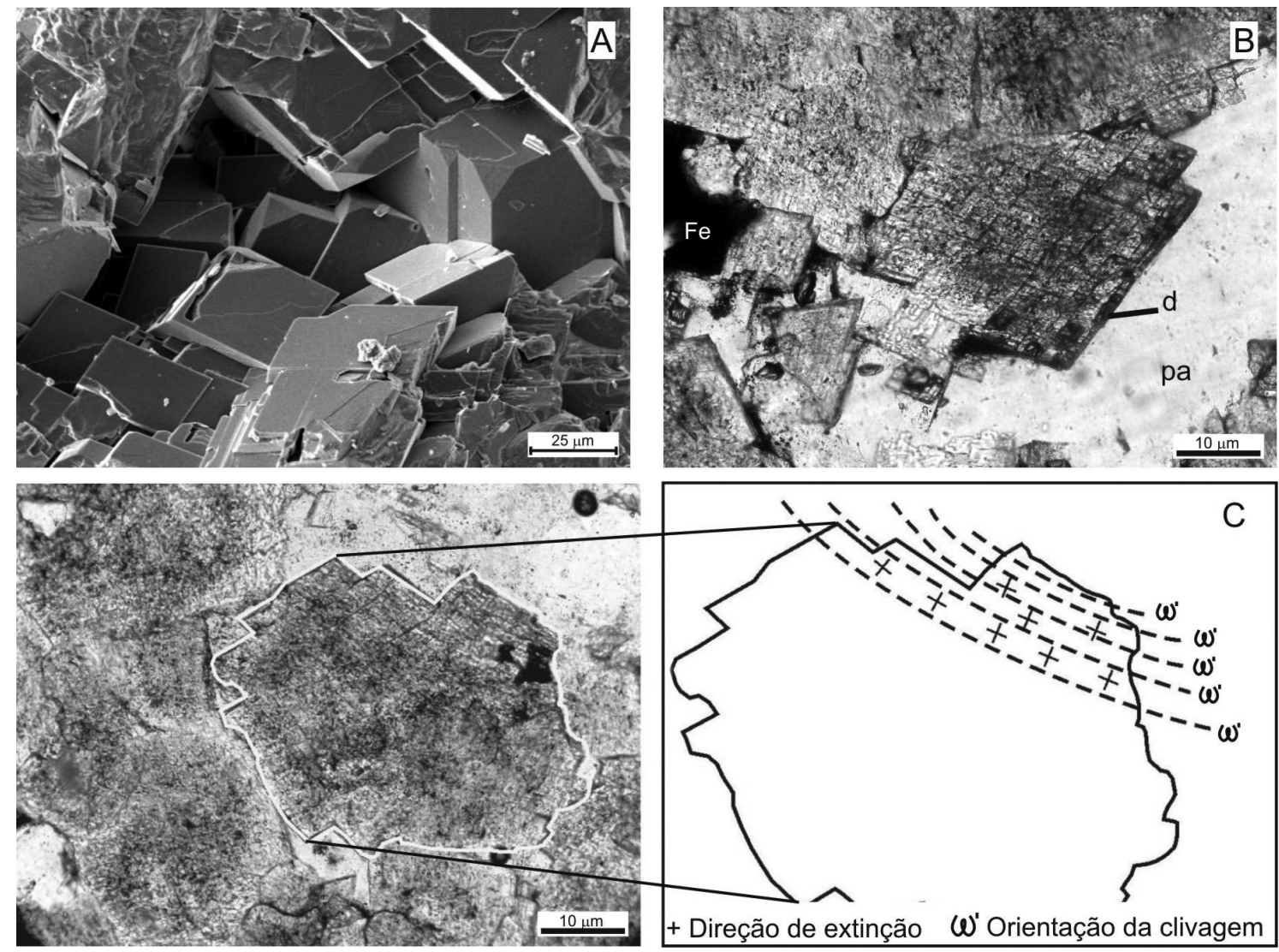

Figura 5 - Variação morfológica da dolomita na Sucessão 1: A) Imagem de microscopia eletrônica (MEV) mostrando textura idiotópica da dolomita. B) Cristal idiotópicos de dolomita (d) preenchendo parcialmente poros agigantados (pa). C) Cristal de dolomita com a direção de extinção representada graficamente ( $\left.\omega^{\prime}\right)$. O diâmetro acima de $30 \mu \mathrm{m}$ e a direção óptica de crescimento do cristal coincidem com a região de maior divergência da clivagem, o que caracteriza uma saddle dolomite.

\begin{tabular}{|c|c|c|}
\hline \multicolumn{3}{|l|}{ A } \\
\hline Amostra & $\delta^{13}$ C VPDB & $\delta^{18}$ OvPDB \\
\hline 1 & $-2,19$ & $-5,12$ \\
\hline 2 & $-1,7$ & $-3,78$ \\
\hline 3 & $-3,16$ & $-5,09$ \\
\hline 4 & $-3,54$ & $-4,8$ \\
\hline 5 & $-3,35$ & $-4,16$ \\
\hline 6 & $-3,45$ & $-3,94$ \\
\hline 7 & $-3,51$ & $-4,37$ \\
\hline 8 & $-3,56$ & $-5,17$ \\
\hline 9 & $-2,86$ & $-4,24$ \\
\hline
\end{tabular}

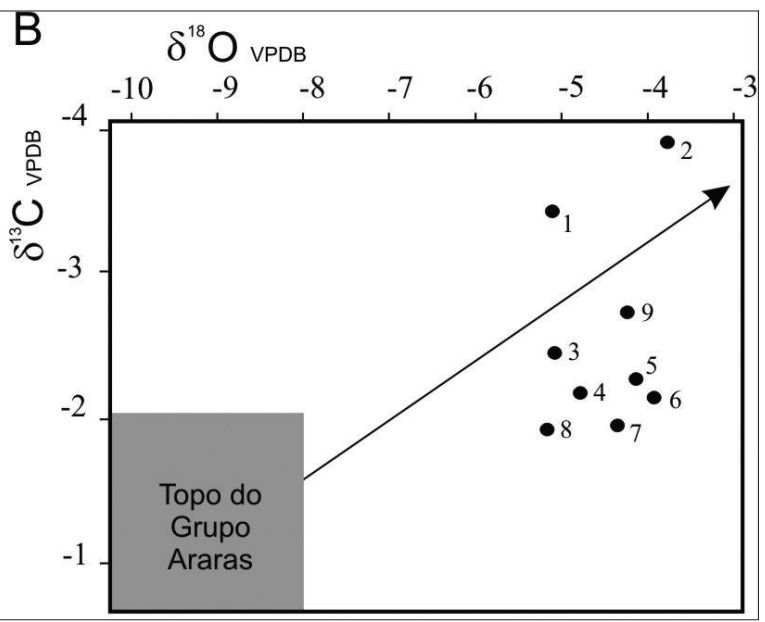

Figura 6 - Quadro com os valores isotópicos do cimento de dolomita e gráfico de valores $d e{ }^{13} \mathrm{C}$ versus ${ }^{18} \mathrm{O}$ para o cimento de dolomita dos quartzo-arenitos da Sucessão 1. Os valores isotópicos são expressos em \%o. A zona destacada representa a variação dos isótopos de C e O do topo do Grupo Araras, segundo Nogueira et al. (2007). A seta indica $o$ "trend" de empobrecimento a partir dos carbonatos dolomitizados do topo do Grupo Araras. 
rocha, substituindo também parte dos grãos de quartzo. Grãos de quartzo cimentados por dolomita são comumente corroídos e cauterizados em suas bordas ( $c f$. Tucker 1992). A porosidade é classificada como secundária, moldica e/ou vesicular, segundo a classificação de Murray (1960) e varia nos arenitos de $2 \%$ até $4 \%$.

Isótopos de carbono e oxigênio A avaliação do sinal isotópico de carbono e oxigênio de carbonatos é um procedimento comumente desenvolvido nas sucessões neoproterozóicas com o intuito de determinar as varia- ções seculares da composição original da água do mar (Jacobsen \& Kaufman 1999). Entretanto, na avaliação de cimentos, os dados de $\delta^{13} \mathrm{C}$ e $\delta^{18} \mathrm{O}$ constituem uma ferramenta importante para indicar a influência de fluídos diagenéticos durante a sua precipitação. Os dados isotópicos contribuem no entendimento do tempo e posicionamento estratigráfico do cimento, a fim de predizer sua gênese e a distribuição na rocha encaixante (Rosen \& Holdren Jr. 1986). O cimento dolomítico apresenta valores de $\delta^{13} \mathrm{C}$ variando de $-1,70$ a $-3,56 \%$, sendo que os valores mais empobrecidos, menores que

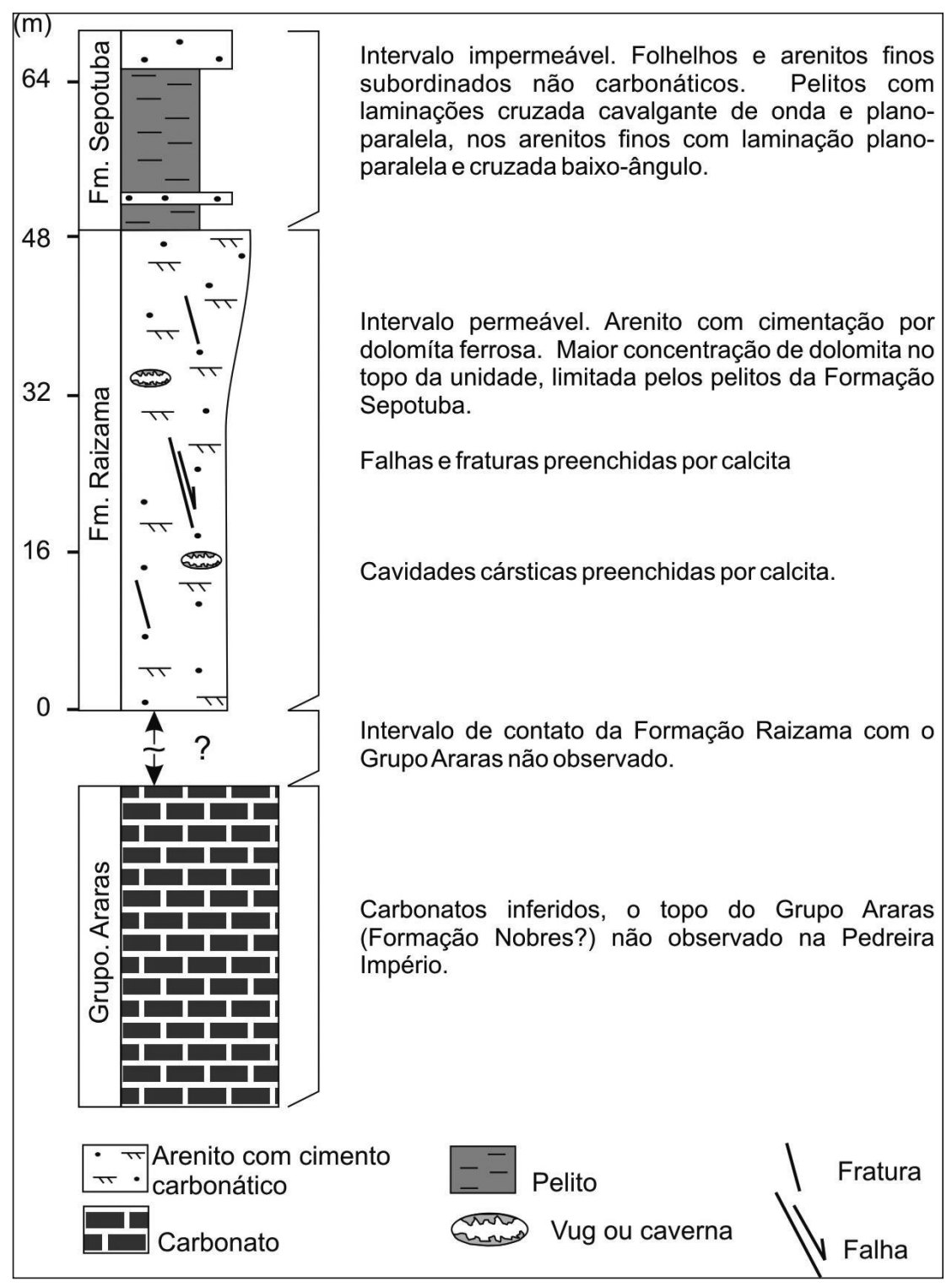

Figura 7 - Modelo para a concentração de cimento de dolomita na sucessão estudada. Arenitos com cimento dolomítico da Sucessão 1 (Formação Raizama) ocorrem limitados provavelmente pelos carbonatos do Grupo Araras e pelos folhelhos da Sucessão 2 (Formação Sepotuba), gerando intervalo permeável confinado entre rochas de baixa permeabilidade. A percolação de fluidos advindos dos carbonatos Araras, usando falhas e fraturas como condutos, teriam propiciado a dissolução parcial dos arenitos e precipitação do cimento dolomítico com valores isotópicos de $\mathrm{C}$ e $\mathrm{O}$ mais empobrecidos. 
$-3 \%$, perfazem dois terços das amostras analisadas (Fig. 6). Os valores de $\delta^{18} \mathrm{O}$ encontrados para a dolomita oscilam entre $-3,78$ a $-5,17 \%$, com valores inferiores a -5 \%o para um terço das amostras (Fig. 6). A relação $\delta^{13} \mathrm{C}$ e $\delta^{18} \mathrm{O}$ não mostra covariância dos valores e nem variam estratigraficamente com a profundidade (Fig. 2,6 ). Comparando estes valores isotópicos com aqueles encontrados no topo do Grupo Araras, posicionado abaixo da sucessão estudada, verifica-se uma diferença significativa, pois os dolomitos da Formação Nobres exibem valores de $\delta^{13} \mathrm{C}$ ligeiramente negativos e próximos de zero (Nogueira et al. 2007).

A origem do cimento de dolomita $\mathrm{O}$ cimento de dolomita, com textura hipidiotópica a idiotópica, ocorre preenchendo fraturas e porosidade secundária, esta gerada a partir da dissolução de grãos com cimentação primária de sílica (sobrecrescimento sintaxial). Além disso, não foi observado carbonato microcristalino ou qualquer crescimento de cristal indicativo de neomorfismo (cf. Tucker 1992). A ocorrência de dolomita tipo "sela" (saddle dolomite) indica soterramento profundo compatível com a mesodiagênese, durante a qual podem se associar estágios de migração de hidrocarbonetos e formação de mineralização de sulfetos (Radke \& Mathis 1980). Hidrocarbonetos associados à dolomita tipo "sela" e esfalerita são descritos na base do Grupo Araras (Nogueira 2003). A distribuição do cimento de dolomita restrito aos arenitos sugere que este foi gerado num intervalo permeável limitado no topo e na base por camadas de baixa permeabilidade (Fig. 7). Os pelitos da Sucessão 2, juntamente com os carbonatos do Grupo Araras, podem ter exercido a função de armadilha estratigráfica que favoreceu o aprisionamento e a percolação dos fluidos ricos em carbonato (Fig. 7). As falhas, fraturas e megacavidades, preenchidas por cimento de dolomita e secundariamente calcita, podem representar os condutos de percolação de fluidos ou para sua remobilização posterior. $\mathrm{O}$ cimento de calcita é restrito às fraturas e cavidades de dissolução e pode representar uma fase final de cimentação, já com o arcabouço da rocha completamente fechado pela dolomita. Os poros no cimento de dolomita, algumas vezes preenchidos por calcita, sugerem uma fase de dissolução parcial no arenito. Os argilominerais autigênicos desenvolvidos em poros agigantados de arenitos dolomíticos do topo da Sucessão 1, podem ter sua origem derivada da alteração e dissolução de feldspatos.

A relação $\delta^{13} \mathrm{C}$ e $\delta^{18} \mathrm{O}$ não mostra covariância dos valores, indicando que fluídos diagenéticos participaram na precipitação do cimento. Os valores geralmente empobrecidos de $\delta^{13} \mathrm{C}$ e $\delta^{18} \mathrm{O}$ são compatíveis com cimentos tardios e podem representar o reflexo da mistura entre fluidos hidrotermais e fluidos meteóricos ricos em carbonato de cálcio (Lee \& Boles 1996). Estas informações corroboram a origem diagenética tardia da dolomita formada durante soterramento profundo (deep burial; Tucker 1992). Os valores de $\delta^{13} \mathrm{C}$ do cimento dolomitico são mais empobrecidos se comparados com os dados de isótopos medidos nos carbonatos do topo do Grupo Araras, cujos valores estão em torno de -2 a 0 \% (cf. Nogueira et al. 2006) e atestam precipitação a partir de mistura de água isotopicamente mais leve (cf. Rosen \& Holdren Jr. 1986, Kah 2000). A origem do cimento carbonático da Sucessão 1 pode ser explicada pela migração de fluídos hidrotermais e/ou remobilização de fluídos aquecidos durante a diagênese, oriundos da dissolução parcial de carbonatos do topo do Grupo Araras (Fig. 7).

CONCLUSÕES A interpretação paleoambiental e estratigráfica do Grupo Alto Paraguai na região do município de Mirassol d'Oeste levou à individualização de sete fácies sedimentares constituídas de siltitos, pelitos e arenitos. Os ambientes da Formação Raizama na região de Mirassol d'Oeste são atribuídos à face de praia, com base na presença de tempestitos, e provavelmente planície de maré, sugerida pela presença de gretas de contração, pseudomorfos de cristais de evaporitos e vários tipos de estratificação cruzada. A predominância de processos de suspensão alternados com influxo esporádico de areia e a presença de estruturas de onda e tipo swaley, são sugestivas de plataforma marinha influenciada por ondas e tempestades.

As fácies da Formação Sepotuba são interpretadas como pertencentes a uma plataforma marinha influenciada por ondas, com predominância de pelitos laminados, lateralmente contínuos compatíveis com uma plataforma marinha distal influenciada por fluxo combinado de tempestades, conforme indicado pela presença de estratificações cruzadas swaley.

O contato entre os arenitos da Formação Raizama e pelitos da Formação Sepotuba na região de Mirassol d'Oeste é brusco e interpretado como um limite de seqüência superimposto por uma superfície transgressiva, que registra evento de inundação que recobriu em onlap uma zona litorânea (Formação Raizama). A ocorrência de cimento de dolomita tardia e a ausência de carbonatos deposicionais marinhos ou feições de neomorfismo nos depósitos siliciclásticos considerados da Formação Raizama, exclui definitivamente a comparação destas rochas com os carbonatos do Grupo Araras. Os dados petrográficos e isotópicos de $\mathrm{C}$ e $\mathrm{O}$, indicam que esta cimentação dolomítica foi resultante, possivelmente, da percolação (remobilização) de fluidos carbonáticos oriundos das unidades dolomíticas do topo do Grupo Araras. A identificação das formações Raizama e Sepotuba na região de Mirassol d'Oeste melhora a resolução dos mapas geológicos existentes desta região, e a importância da distinção da Formação Sepotuba na região de Mirassol d'Oeste é seu resgate como unidade distinta do Grupo Alto Paraguai o que contribui no melhor entendimento da história evolutiva do final do Neoproterozóico na parte sul do Cráton Amazônico.

Agradecimentos Este trabalho é parte da dissertação de mestrado do primeiro autor, financiado pela Coordenação de Aperfeiçoamento de Pessoal do Ensino Superior (CAPES) que concedeu uma bolsa de pesquisa, e Fundação de Apoio à Pesquisa do Estado de São 
Paulo (FAPESP) através dos projetos $n^{\circ} 00 / 02903-8$ e 03/02836-7 coordenados por Claudio Riccomini e Setembrino Petri, respectivamente. Ao Prof. Cláudio La- marão pela obtenção de imagens de MEV na Universidade Federal do Pará.

\section{Referências}

Alkmin F.F., Marshak S., Fonseca M.A. 2001. Assembling West Gondwana in the Neoproterozoic: Clues from the São Francisco Craton region, Brazil: Geology, 29:319322.

Allen P.A. \& Hoffman P.F. 2005. Extreme winds and waves in the aftermath of a Neoproterozoic glaciation. Nature., 433:123-127.

Allen P.A. \& Leather J. 2006. Post-Marinoan marine siliciclastic sedimentation: The Masirah Bay Formation, Neoproterozoic Huqf Supergroup of Oman. Precambrian Research., 144:167-198.

Almeida F.F.M. de. 1964a. Geologia do Centro-Oeste matogrossense. Rio de Janeiro, DNPM, Boletim 215, 1-53 p.

Almeida F.F.M. de. 1964b. Glaciação eocambriana em Mato Grosso. Rio de Janeiro, DNPM, Boletim 117, 1-11 p.

Almeida F.F.M. 1965. Geossiclíneo Paraguaio. In: Centro Acad. Est. Geol. Porto Alegre, Semana de Debates Geológicos, 1, Atas, 87-101p.

Almeida F.F.M. 1984. Província Tocantins, setor sudoeste. In: F.F.M. Almeida \& Y. Hasui (coords.) O Pré-Cambriano do Brasil. São Paulo, Ed. Blücher Ltda, p. 265-281.

Almeida F.F.M., Hasui Y., Brito Neves B.B., Fuck R.A. 1977. Províncias estruturais brasileiras. In: SBG, Simpósio de Geologia do Nordeste, 7, Campina Grande, Resumos, p. 363-391.

Almeida, F.F.M. de \& Mantovani, M.S.M. 1975. Geologia e geocronologia do Granito de São Vicente, Mato Grosso. Anais da Academia Brasileira de Ciências, 47:451-458.

Alvarenga C.J.S., Moura C.A.V., Gorayeb R.S.S, Abreu F.A.M. 2004. Paraguay and araguaia Belts. In: U.G. Cordani, E.J. Milani, A. Thomaz Filho, D.A. Campos (eds.) Tectonic Evolution of South America. Rio de Janeiro, ABC/DNPM/MTC/CNPq/FINEP/ANP, p.183-193.

Alvarenga C.J.S. \& Saes G.S. 1992. Estratigrafia e sedimentologia do Proterozóico Médio e Superior da região Sudeste do Craton Amazônico. Rev. Bras. Geoc., 22(4):493-499.

Alvarenga C. J. S. \& Trompette R. 1992. Glacially influenced sedimentation in the Late Proterozoic of Paraguai Belt (Mato Grosso, Brasil). Palaegeogr. Paleoclimatol. Paleoecol., 92:85-105

Barros A.M., Silva R.H.da, Cardoso O.R.F.A., Freire A.F., Souza Jr. J.J. de, Rivetti M., Luz D.S. da, Palmeira R.C. de B., Tassinari C.C.G. 1982. Geologia, geomorfologia, pedologia, vegetação, uso potencial da terra. In: BRASIL (ed). Geologia da Folha SD.21 Cuiabá. Rio de Janeiro, DNPM, Projeto RADAM. cap. 1, p.25-192. (Levantamento de Recursos Naturais, 26).

Basei M.A.S. \& Brito Neves B.B. 1992. Características geológicas da transição Proterozóico-Faneorozóico no Brasil. In: J.G. Gutierrez Marco \& I. Rábano (eds.) Paleozoico Inferior de Iberoamérica. Mérida, Universidad de Extremadura, p. 331-342.
Cheel R.J. \& Leckie D.A. 1993. Hummocky cross-stratification. In: V.P. Wright (ed.) Sedimentology Review. Cambridge, Blackwell Scientific Publication. p. 103-122.

Choquette P.W. 1971. Late ferroan dolomite cement, Mississippian carbonates, Illinois basin, U.S.A. In: O.P. Bricker (ed.) Carbonate ciments. The Johns Hopkins University, v. 19, p.339-346.

Condon D., Zhu M., Bowring S., Wang W., Yang A., Jin Y. 2005. U-Pb Ages from the Neoproterozoic Doushantuo Formation, China. Science, 308:95-98.

Dalrymple R.W. 1992. Tidal depositional systems. In: R.G. Walker \& N.P. James (eds.) Facies Models: response to sea level change. Ontario, Geol. Assoc. Canada, 454p.

Dalrymple R.W., Zaitlin B.A., Boyd R. 1992. Estuarine facies models; a conceptual basis and stratigraphic implications. J. Sed. Petrol., 62(6):1130-1146.

De Raaf J.F.M., Boersma J.R., Van Gelder A. 1977. Wavegenerated structures and sequence from a shallow marine succession, Lower Carboníferous, County Crok, Ireland. Sedimentology, 24(4):451-483.

Duke W.L. \& Prave A.R. 1992. Storm-and tide-influenced prograding shoreline sequences in the Middle Devonian Mahantango Formation, Pennsylvania. In: D.G. Smith, G.E. Reison, B.A. Zaitlin, R.A. Rahmani (eds.) Clastic Tidal Sedimentology. Canadian Soc. Petrol. Geol., p. 49370 (Memoir 16).

Folk R. L. 1974. Petrology of Sedimentary Rocks. Hemphill Publishing Co., Drawer M. University, 182p.

Folk R.L. \& Assereto R. 1974. Giant aragonite rays and baroque white dolomite in tepee-fillings, Triassic of Lombardy, Italy (abs.): Am. Assoc. Petroleum Geologists, Abs. with Program, Ann. Mtng., San Antonio. p. 34-35.

Goodall T.M., North C.P., Glennie K.W. 2000. Surface and subsurface sedimentary structures produced by crusts. Sedimentology, 47:99-118.

Halverson G., Maloof A., Hoffman P.F. 2004. The Marinoan glaciation (Neoproterozoic) in northeast Svalbard, Basin Res. 16:297-324.

Halverson G.P., Hoffman P.F., Schrag D.P., Maloof A.C., Rice A.H. 2005. Toward a Neoproterozoic composite carbon-isotope record. Geol. Soc. Amer. Bull., 117:11811207.

Hoffman P.F. \& Schrag D.P. 2002. The Snowball Earth hyphothesis: testing the limits of global change: Terra Nova, 14:129-155.

Jacobsen S.B. \& Kaufman A.J. 1999. The Sr, C and O isotopic evolution of Neoproterozoic seawater. Chem. Geol. 161:37-57.

Jiang G.G., Christie-Blick N., Kaufman D.M.B., Banerjee D.M., Rai Vibhuti. 2002. Sequence stratigraphy of the Neoproterozoic Infra Krol Formation and Krol Group, Lesser Himalaya, India. J. Sediment. Res., 72:524:542

Kah L.C. 2000. Preservation of deposicional $\delta 13 \mathrm{C}$ signature 
in Proterozoic dolostone: geochemical constraints on seawater chemistry and early diagenesis. In: J.P. Grotzinger \& N.P. James (eds.) Carbonate sedimentation and diagenesis in the evolving Precambrian world. SEPM, p.345-360 (Special Publication, 67).

Kaufman A.J. \& Knoll A.H. 1995. Neoproterozoic variations in the C-isotopic composition of seawater: stratigraphic and biogeochemical implications. Precamb. Res., 73:2749.

Knoll A. H. 2000. Learning to tell Neoproterozoic time. Precamb. Res., 100:3-20.

Lee Y.I. \& J. Boles. 1996. Depositional control on carbonate cement in the San Joaquin basin, Califórnia. In: L.J. Crossey, R. Loucks, M.W. Totten, (eds.) Siliciclastic diagenesis and fluid flow: Concepts and applications. SEPM, Special Publication, v.55, p.13-22.

Murray R.C. 1960. Origin of porosity in carbonate rocks. Journal of Sedimentary Petrology, 30:59-84.

Myrow P.M. 1992. Pot and gutter casts from the Chapel Island Formation, southeast Newfoundland. J. Sediment. Petrol. 62:992-1007

Narbonne G.M., Kaufman A.J., \& Knoll A.H. 1994. Integrated chemostratigraphy and bioestratigraphy of the upper Windermere Supergroup (Neoproterozoic), northwestern Canada: Implications for Neoproterozoic correlations and the early evolution of animals. Geol. Soc. Am. Bull., 106:1281-1292.

Nogueira A. C. R. 2003. A plataforma carbonática Araras no sudeste do Cráton Amazônico, Mato Grosso: Estratigrafia, contexto paleoambiental e correlação com os eventos glaciais do Neoproterozóico. São Paulo, Tese de Doutoramento, Universidade de São Paulo, 173 p.

Nogueira, A.C.R \& Riccomini, C. 2006. O Grupo Araras da Faixa Paraguai Norte, Sul do Cráton Amazônico. Rev. Bra. Geoc., 36(4):623-640.

Nogueira A.C.R., Riccomini C., Sial, A.N., Moura C.A.V., Fairchild T.R. 2003. Soft-sediment deformation at the base of the Neoproterozoic Puga cap carbonate (southwestern Amazon Craton, Brazil): Confirmation of rapid icehouse to greenhouse transition in snowball Earth. Geology, 31(7):613-616.

Nogueira A.C.R, Riccomini C., Sial A.N., Moura C.A.V., Trindade R.I.F., Fairchild T.R. 2007. Carbon and strontium isotope fluctuations and paleoceanographic chang- es in the late Neoproterozoic Araras carbonate platform, southern Amazon craton, Brazil. Chemical Geology, 237:168-190.

Radke B.H. \& Mathis R.L. 1980. On the formation and occurrence of saddle dolomite. J. Sediment. Petrol., 50:1149-1168.

Rosen M.R. \& Holdren JR. G.R. 1986. Origin of dolomite cement in Chesapeake Group (Miocene) siliciclastic sediments: an alternative model to burial dolomitization. J. Sediment. Petrol., 56(6):788-798.

Silva Jr. J. B. C. de, Nogueira A.C.R., Petri S., Ridalgo R.L., Trindade R.I.F. 2006. Gretas de contração em limite de seqüência Neoproterozóico: um exemplo do Grupo Alto Paraguai, SW do Cráton Amazônico. In: Simpósio de Geologia da Amazônia, 9, Resuno, CD-ROM.

Tohver E., D'Agrella Filho M.S., Trindade, R.I.F. 2006. Paleomagnetic record of Africa and South America for the 1200-500 Ma interval, and evaluation of Rodinia and Gondwana assemblies. Precambrian Research, 147: 193-222.

Tucker M.E. 1992. Sedimentary Petrology: an introduction to the Origin of sedimentary rocks. 2ed. Blackwell Scientific Publications, $260 \mathrm{p}$.

Van Wagoner J.C., Posamentier H.W., Mitchum R.W., Vail P.R., Sarg J.F., Loutit T.S., Handerbol J. 1988. An overview of the fundamentals of sequence stratigraphy and key definitions. In: C.K. Wilgus, B.S. Hastings, C.A. Ross, H.W. Posamentier, J.C. Van Wagoner, C.G.S.C. Kendall (eds.) Sea-Level Changes: An Integrated Approach. Tulsa, SEPM, p.39-46 (Special Publication, 42).

Walker R.G. \& Plint A.G. 1992. Wave- and storm-dominated shallow marine systems. In: R.G. Walker \& N.P. James (eds.) Facies Models: Response to Sea Level Changes. Ontario, Canada, Geol. Assoc. Can., p.219-239.

Walter M.R., Veevers J.J., Calver C.R., Gorjan P., Hill A.C. 2000. Dating the 840-544 Ma Neoproterozoic interval by isotopes of strontium, carbon, and sulfur in seawater, and some interpretative models. Precamb. Res., 100:371-433

Manuscrito AE 067/2006

Submetido em 12 de janeiro de 2007 Aceito em 15 de setembro de 2007 